\title{
The impact of peripheral circulation characteristics of typhoon on sustained ozone episodes over the Pearl River Delta region, China
}

\author{
Ying $\mathrm{Li}^{1,2}$, Xiangjun Zhao ${ }^{1,2,3^{*}}$, Xuejiao Deng ${ }^{4 *}$, Jinhui Gao ${ }^{1,2,5}$ \\ ${ }^{1}$ Department of Ocean Sciences and Engineering, Southern University of Science and Technology, Shenzhen, China \\ ${ }^{2}$ Southern University of Science and Technology, Shenzhen, China \\ ${ }^{3}$ School of Mathematics and Finance, Chuzhou University, Anhui 239000, China \\ ${ }^{4}$ Institute of Tropical and Marine Meteorology/Guangdong Provincial Key Laboratory of Regional Numerical Weather \\ Prediction, China Meteorological Administration, Guangzhou, China \\ ${ }^{5}$ Plateau Atmosphere and Environment Key Laboratory of Sichuan Province, School of Atmospheric Sciences, Chengdu \\ University of Information Technology, Chengdu, China. \\ * Corresponding author e-mail address: (iamzxj841025@163.com) and (dxj@gd121.cn)
}

\begin{abstract}
It is widely reported that the peripheral circulation of typhoon favors for the formation of sustained ozone episodes. However, the process how it impact on the day-to-day ozone pollution levels during the episodes have not been clearly studies, which is crucial for better prediction of the daily ozone variation. In this study, the analysis of ground observation, wind profile data, and model simulation are integrated. By analyzing the wind profile radar observations, we found a weak winds deepening (WWD; vertical depth of the weak winds increased), which is more correlated to the ground-level ozone variation than surface weak wind. Long-term statistical analyses show that the WWD is a common weather phenomenon that occurs in the peripheral subsidence region of typhoons and was generally accompanied by ozone pollution episodes. WRF-Chem with process analysis simulation show that under the impact of the peripheral subsidence chemical formation (CHEM) and vertical mixing (VMIX) effects are two major contributors to the enhancement of ozone levels, while the advection (ADV) are always negative values. But regarding the daily variability of the daytime ozone levels during the episode, it do not determined by the daily variation of daytime CHEM and VMIX, but that of the ADV term. A detail day-to-day analysis show that weak subsidence associated with typhoon periphery provide the premise for the clear sky and warmer air, which is conducive for the ozone photolysis formation (CHEM) above the ground in planetary boundary layer (PBL) and compensate the ozone through the positive VMIX effects on the ground. The WWD induced by the peripheral circulation of typhoon system provide the premise for the day-to-day positive contribution of ADV term to ozone enhancement throughout the whole planetary boundary layer (PBL), which play an important role in determining the day-to-day daytime ozone variation. These results indicate the important role of the WWD in the lower troposphere for the formation of sustained ozone episodes due to the peripheral circulation of the typhoon, which helps to better predict the daily changes of daytime ozone levels.
\end{abstract}




\section{Introduction}

The Pearl River Delta (PRD) located in the coastal region of South China, which is often affected by typhoon systems, has experienced major economic development and urbanization in the past two decades, and has been accompanied by large increases in air pollution and decreases in visibility (Wang et al., 1998, 2001; Lai and Sequeira, 2001). Ozone pollution is the most important air pollution issue in this region; ozone has been the 'primary pollutant' since 2014 (Ministry of Ecology and Environment of China, 2016). Ozone is harmful to human health and has adverse effects on vegetation and crops, among others(Aunan et al., 2000; Felzer et al., 2007; Feng et al., 2015). Ozone concentrations are determined by the photochemical reactions of its precursors and by the local meteorological conditions. However, ozone pollution episodes are mainly triggered by weather conditions rather than by sudden increases from emission sources(Ziomas et al., 1995; Giorgi and Meleux, 2007; Lin et al., 2019).

The Guangdong Haze Weather Bulletin(Wang, 2017) has classified the weather patterns affecting regional pollution events into cold fronts, cold high-pressure systems moving towards the sea, uniform pressure fields, Western Pacific subtropical high (WPSH), tropical cyclone (TC) peripheries, and weak cold high-pressure ridges. By using observational data, several studies have reported the impacts of TC activity on meteorological factors that are favourable for air pollution over the PRD region(Feng et al., 2007; Chen et al., 2008; Wu et al., 2013). TCs are typical weather systems that are responsible for both high ozone and $\mathrm{PM}_{2.5}$ pollution over the $\mathrm{PRD}(\mathrm{Chen}$ et al., 2008; Deng et al., 2019).

Many studies in the PRD region and other coastal regions of China have shown the significant impact of TCs on forming ozone (TCs-Ozone) episodes in recent years(Zhang et al., 2012; Li et al., 2013, 2014; Zhang et al., 2013; Jiang et al., 2015; Huang et al., 2015; Shu et al., 2016, 2019; Tan et al., 2018; Chen et al., 2018; Han et al., 2019). TCs-Ozone episodes generally occur when weather conditions include high temperatures, radiation flux, low relative humidity, and weak winds(Cheng et al., 2016; Liu et al., 2017). There were large amount of observational-based studies reporting the TCs-Ozone episodes are weak wind related, however it is very few about the study of the influence mechanism of weak wind on ozone in TCs-Ozone episodes. In addition, previous integrated process rate(IPR) analysis based on numerical modelling simulations have reported that the chemical (CHEM) and vertical mixing (VMIX) effects are two major 

concentration enhancement. the TCs-Ozone episodes have been widely reported, the studies of mechanism on the daily daytime variation of during sustained TCs-Ozone episodes are quite limited. variation of daytime ozone concentration in TCs-ozone episode. The analysis of ground observation, wind profile data, and WRF-Chem model simulation with process analysis are integrated. Detailed data and model description are provided in Sect. 2, followed by the results and discussion in Sect. 3. The last section summaries the main conclusions.

\section{Data and model}

\subsection{Data}

In this study, hourly surface ozone concentrations from 2016 over mainland China were obtained from the Ministry of Environmental Protection of China. The 3D wind profiler data, automatic weather station data, cloud data, and solar radiation measurements were provided by the China Meteorological Administration and were used for the meteorological analyses of Typhoon Nepartak. The Final (FNL) Operational Global Analysis data that were used to describe the circulation of Typhoon Nepartak have a horizontal resolution of $1^{\circ} \times 1^{\circ}$ with 27 vertical levels and were obtained from the National Centers for Environmental Prediction(NCEP), USA . 
(Fig. S2). At 05:50 on 8 July, the typhoon made landfall in Taitung County, Taiwan, with a maximum wind speed of $60 \mathrm{~m}$ $\mathrm{s}^{-1}$, and again in Shishi City, Fujian at 14:00 on 9 July, with a maximum wind speed of $23 \mathrm{~m} \mathrm{~s}^{-1}$. At 03:00 on $10 \mathrm{July}$, the typhoon weakened into a tropical depression.

\subsection{Model descriptions}

WRF-Chem is a widely used and fully coupled online 3D Eulerian chemical transport model

(https://ruc.noaa.gov/wrf/wrf-chem/) that considers both chemical and physical processes(Zhang et al., 2010; Forkel et

al., 2012); version 3.9.1.1 was applied in this study. Detailed descriptions of the meteorological and chemical aspects of conditions for D2, which covered most of southern China. located in the lowest $2 \mathrm{~km}$ to fully describe the vertical structure of the PBL. Carbon Bond Mechanism Z (CBM-Z), which includes 133 chemical reactions for 53 species and extends the model framework to function for a longer time period and at a larger spatial scale than its predecessor, was used as the gas-phase chemical mechanism(Zaveri and Peters, 1999). The corresponding aerosol chemical mechanism was the Model for Simulating Aerosol Interactions and accuracy of the aerosol model calculations. Other major model configuration settings are listed in Table 1.

Table 1. Major model configuration options used in the simulations.

\begin{tabular}{ll}
\hline \multicolumn{1}{c}{ ITEM } & Selection \\
\hline Long wave radiation & RRTMG \\
Shortwave radiation & RRTMG \\
Microphysics scheme & Lin scheme \\
\hline
\end{tabular}




\begin{tabular}{ll}
\hline Boundary layer scheme & Yonsei University (YSU) scheme \\
Land surface option & Noah land surface model \\
Photolysis scheme & Fast-J photolysis \\
Dry deposition & Wesely scheme \\
\hline
\end{tabular}

\section{Results and discussion}

\subsection{Episodic data analysis}

The ozone pollution level and the meteorological conditions of the typhoon Nepartak case was first analyzed. As shown in Fig. 1, Guangdong province experienced a sever ozone pollution during the period. 28\% (7 July) to 57\% (10 July) of the air quality stations in Guangdong Province exceeded the national air quality standard level-II for ozone $\left(200 \mu \mathrm{g} \mathrm{m}^{-3}\right)$ at the daily peaks (16:00 LST). To show the vertical motion of the typhoon centre and peripheral region, we constructed a cross section through the typhoon system (points A and B; Fig. 2a-d) and plotted the corresponding vertical velocities (Fig. 2e-h) using the NCEP data. As shown in Fig. 2e-f, the western subsiding branches of vertical typhoon circulation were located over the PRD during 7-8 July, when ozone concentrations increased significantly compared to those of 6 July. After Typhoon Nepartak made landfall at Shishi City on 9 July, the peripheral subsidence had moved to the western area of the PRD region (Fig. $2 \mathrm{~g}-\mathrm{h}$ ) and the PRD region was influenced by weak vertical motion and a weak horizontal wind field. Peak ozone levels exceeded $100 \mathrm{ppb}$ at most of the monitoring stations in the PRD at this time. On 11 July, Typhoon Nepartak dissipated and the surface ozone concentrations began to decrease (Fig. 1f).

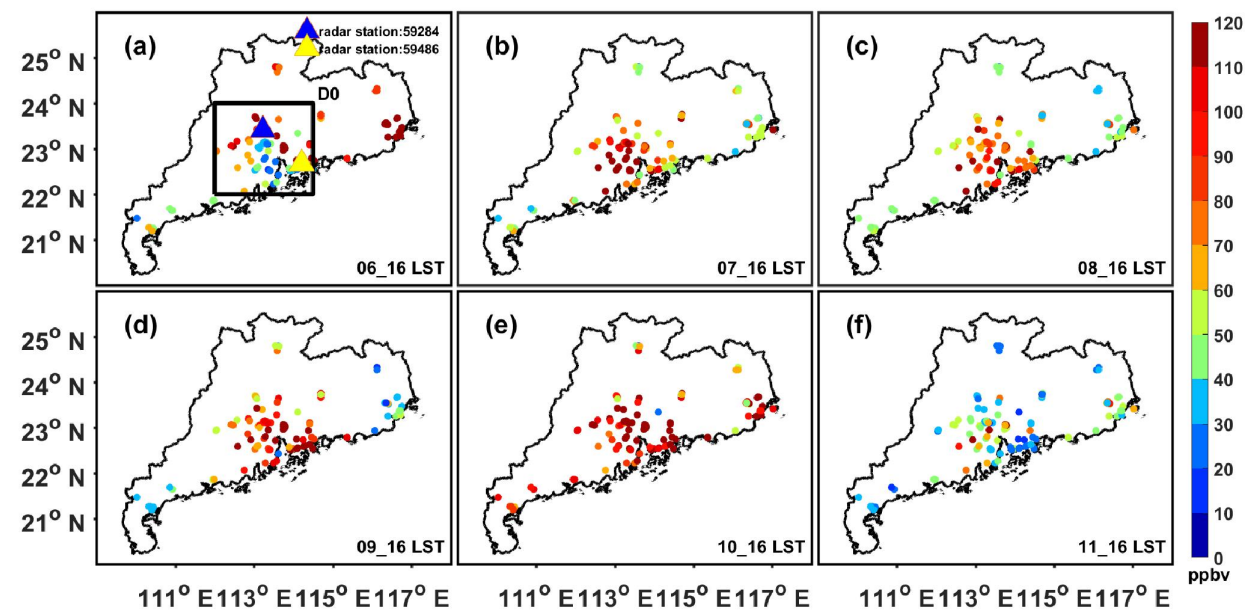

Figure 1. The horizontal distribution of surface ozone concentration over PRD at 16:00 from (a) 6 July 2016 to (f) 11 July 2016. The yellow 

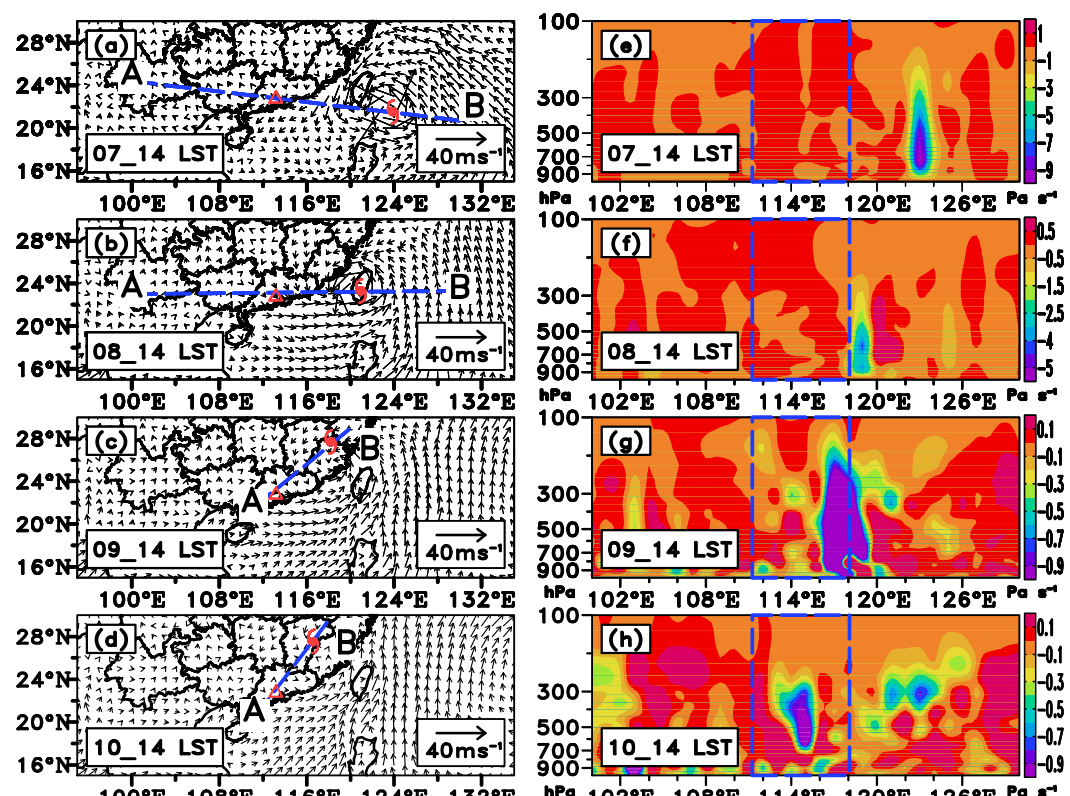

Figure 2. (a)-(d) $1000 \mathrm{hPa}$ wind vectors of NCEP-FNL data from 14:00 7 July to 14:00 10 July with red triangle and typhoon signs representing PRD center and Nepartak locations, respectively. (e)-(h) vertical cross sections of vertical velocity along the four straight lines linking PRD and the centers of Typhoon Nepartak in (a)-(d) from 14:00 7 July to 14:00 10 July 2016. The four blue dashed boxes denote the longitude range of PRD in (e)-(h).

(Fig. 3b), and high temperatures (Fig. 3c), when the subsiding branches of vertical typhoon circulation were located over the PRD during 7-8 July (Fig. 2e-f). The variations in these surface meteorological variables exhibited favorable conditions for increasing ozone concentrations(Cheng et al., 2016; Liu et al., 2017). However, the height of the PBL increased significantly on 8 and 9 July (Fig. 3c), and the atmosphere was under unstable conditions, which was indicated by the overlapping temperature soundings and the parcel traces below $800 \mathrm{hPa}$ (Fig. 3d-f). This instability is also shown by the large values of convective available potential energy (CAPE; Fig. 3d-f), which is another criterion used to determine the stability of atmosphere. In general, when the CAPE is $\sim 1000 \mathrm{~J} \mathrm{~kg}^{-1}$, the atmosphere is unstable, which is favorable for convection. These results illustrate that, under the control of typhoon periphery, the PBL height can be 

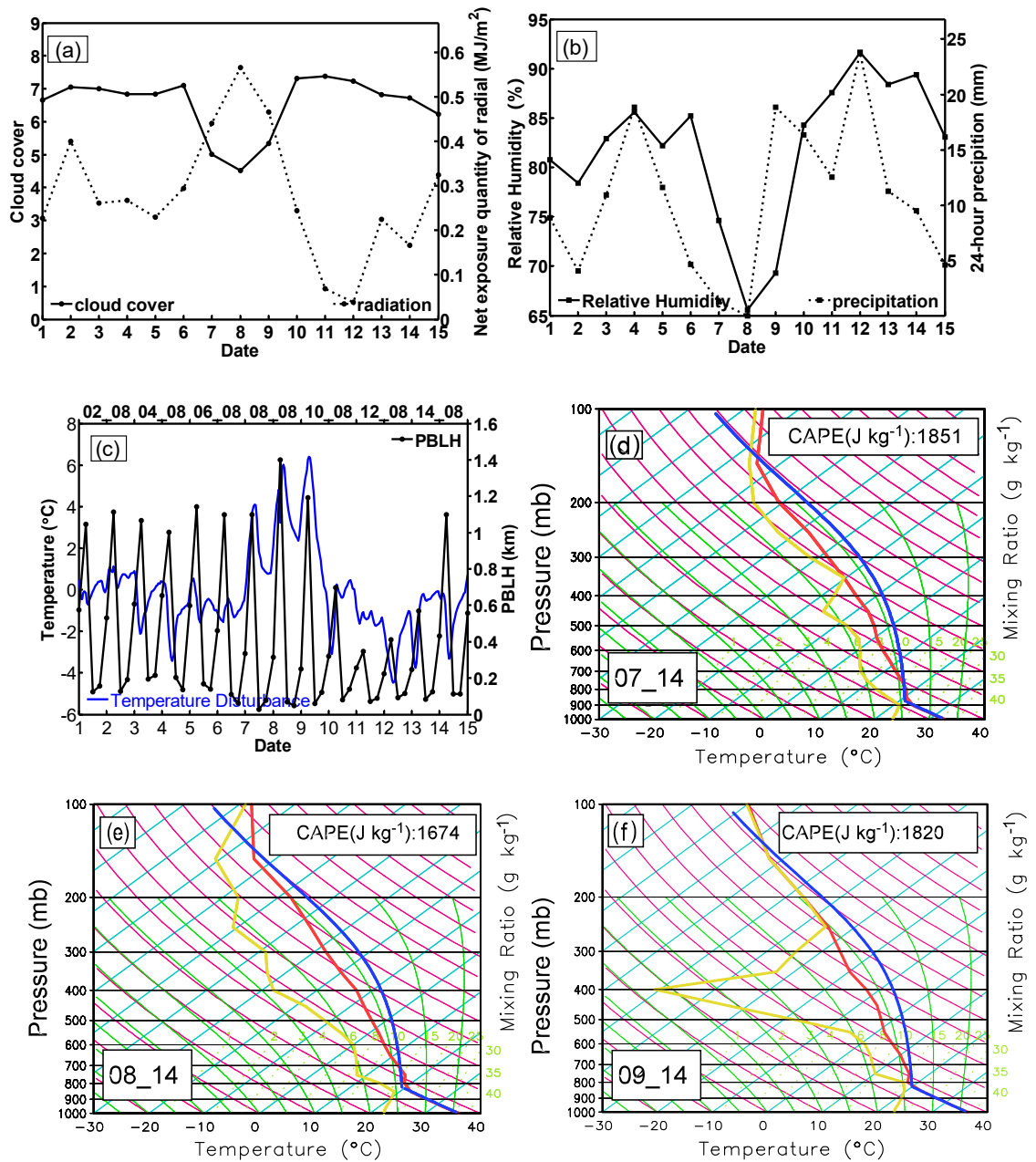

Figure 3. Time series of diurnal mean (a) cloud cover, radiation at 59287 observation station, (b) relative humidity, 24-h precipitation 
dewpoint sounding, respectively.

The evolution of the vertical profile of horizontal winds at representative station 59284 is shown in Fig. 4a. Before 5 July, the wind speed was increasing with the vertical atmospheric layers. There were relatively larger wind speeds above the PBL and relatively weaker wind speeds below $\sim 700 \mathrm{~m}$, with relatively low surface ozone concentrations $(<40 \mathrm{ppbv})$. On 5 July, the daily ozone concentration started to increase ( $>70 \mathrm{ppbv})$ as the depth of WWD increased simultaneously. The depth of WWD was $\sim 3 \mathrm{~km}$ during 7-9 July with a sustained increasing ozone peak. On the night of 11 July, the horizontal wind speed above $\sim 1 \mathrm{~km}$ increased significantly and the ozone concentration decreased sharply. Variations in the wind profile and surface ozone at another representative station are also shown in Fig. 4b. At this station, the depth of WWD started to increase on 7 July, with a gradually increasing ozone peak value. Co-variations of the ozone concentration and WWD at other radar stations were also observed (Fig. S3-5). This co-variation is not a local effect, but is instead a regional phenomenon.
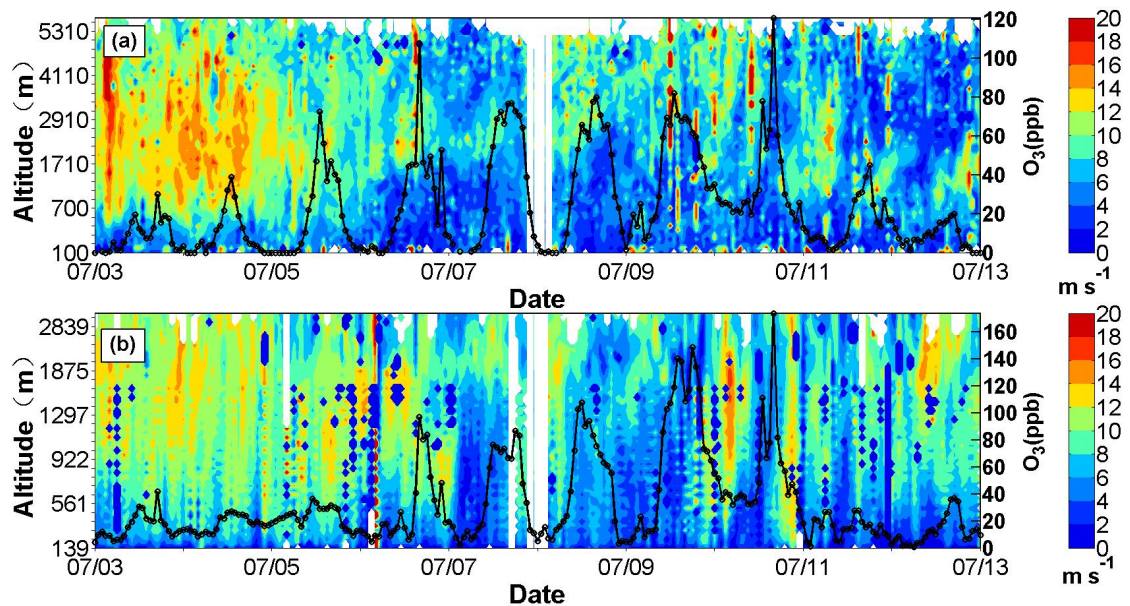

Figure 4. The profile evolution of horizontal wind speed from 3 to 13 July. the black solid lines are the surface ozone concentrations at (a) 59284 and (b) 59486 wind profile radar station.

By analyzing the wind profile data (Fig. 4), we noticed that the vertical depth of the horizontal weak wind generally increased from the surface up to the lower troposphere $(\sim 2-3 \mathrm{~km})$ and the surface ozone concentration changed with the change of vertical depth of the horizontal weak wind. To further illustrate the different impact of the surface weak wind and the WWD on surface ozone concentrations, the correlation coefficients between the surface ozone concentrations 


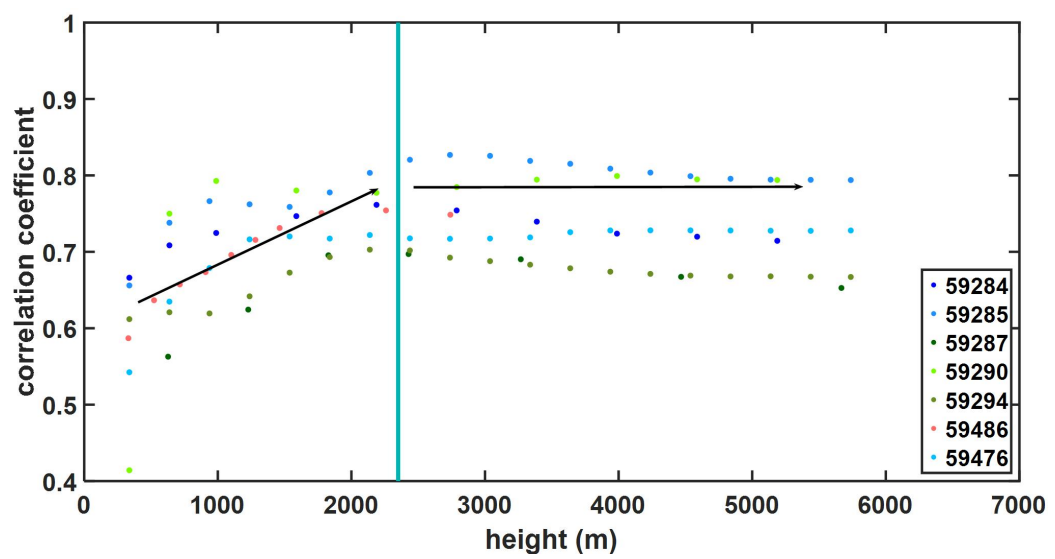

Figure 5. Correlation coefficient between the evolution of average wind speed and the evolution of ground ozone concentration in different altitude ranges of each wind profile radar station.

\subsection{Long-term statistical analysis of the relationship between WWD and the 03 episode}

The above observational analysis shows that there was no stable atmospheric stratification and a decrease in the height of the boundary layer in this ozone pollution episode. The analysis of wind profile radar data and the correlation coefficients between the surface ozone concentrations and the average wind speeds between the surface and the altitude of each vertical layer (up to $6 \mathrm{~km}$ ) indicate that in this episode of ozone pollution, WWD may have played an important role in the increasing of ozone pollution at the surface. Guangdong Province is located on the western coast of the Pacific Ocean and is frequently affected by typhoons annually. To investigate whether the relationship between WWD and ground-level $\mathrm{O}_{3}$ only occurred in this case study or is a common phenomenon, a long-term statistical analysis of historical data was conducted. A statistical analysis of tropical cyclone wind fields in the Northwestern Pacific Ocean from 2014 to 2018 (based on Guangdong wind profiler data) was conducted. As not all the radar stations in Guangdong province are available during a typhoon, the available statistics number of each radar station for the 38 typhoons were 
$\mu \mathrm{g} \mathrm{m}^{-3}$ are harmful to human health(Organization, 2005). The PRD regional background ozone concentration is

generally less than $80-100 \mu \mathrm{g} \mathrm{m}^{-3}$ and the ozone concentrations at most stations can exceed $160 \mu \mathrm{g} \mathrm{m}^{-3}$ (national AQ statistics for the seven radar stations. The average value of $\mathrm{n} / \mathrm{M}$ for the seven radar stations is $93 \%$. This indicates that,

\begin{tabular}{ccc}
\hline Radar station number & $\mathrm{n} / \mathrm{M}$ & $(\mathrm{n} 1+\mathrm{n} 2) / \mathrm{n}$ \\
\hline 59294 & $33 / 38(87 \%)$ & $(21+11) / 33(97 \%)$ \\
59486 & $32 / 33(97 \%)$ & $(18+12) / 32(94 \%)$ \\
59476 & $29 / 30(97 \%)$ & $(22+5) / 29(93 \%)$ \\
59285 & $33 / 36(92 \%)$ & $(21+12) / 33(100 \%)$ \\
59287 & $35 / 38(92 \%)$ & $(23+12) / 35(100 \%)$ \\
59284 & $24 / 25(96 \%)$ & $(19+5) / 24(100 \%)$ \\
59290 & $28 / 30(93 \%)$ & $(13+9) / 28(78 \%)$ \\
Ave. & $93 \%(87 \%-97 \%)$ & $94 \%(78 \%-100 \%)$ \\
\hline
\end{tabular}



simulation.

\subsection{Model simulation and validation}

To investigate the impact of typhoon periphery and WWD on forming the sustained ozone episode, the numerical model with the process analysis was applied in this study. Before applying the model to carry out any analysis, the model performance was validated by using the available observations. Figure S6a-d presents the measured and simulated data for temperatures, wind speeds, wind directions, and ozone concentrations at Guangzhou from 00:00 on 3 July to 07:00 on 15 July 2016. With regards to the meteorological variables, there was good agreement between the measured and modelled results, especially the shifting wind features, implying that the model successfully captured the synoptic features. However, ozone concentrations (Fig. S6d) overestimated low values or underestimated high values some times. But the simulated results and observed data reasonably agreed with each other and captured the ozone episode in the region.

Statistical metrics including the index of agreement (IOA), mean bias (MB), root mean square error (RMSE), and normalised mean bias (NMB) were used to further examine the model performance (Table 3). The IOA of the wind direction was determined according to Kwok et al.(2010), and the IOA values for the other variables were calculated following the approach of $\mathrm{Lu}$ et al.(1997). Generally, our simulation of the time series of ozone concentrations and meteorological variables was reasonable. All the meteorological parameters were close to the corresponding simulation results in the PRD region(Wang et al., 2006; Li et al., 2007; Hu et al., 2016). IOAs for temperature and wind speed (0.89 and 0.66 , respectively) reached the criteria (as presented in the brackets of Table 3). The model performed well at capturing the wind directions, with a small MB of $7.72^{\circ}$. MBs and NMBs for temperature and wind speed exceeded the 

capture the transport features in southern China during this period.

Table 3. Statistical comparison between the observed and simulated variables. The benchmarks are based on Emery et al.(2007) and EPA (Doll, 1991).Values that did not reach the criteria are marked in grey.

\begin{tabular}{lllll}
\hline Variable $^{\mathrm{a}}$ & $\mathrm{IOA}^{\mathrm{b}}$ & $\mathrm{MB}^{\mathrm{b}}$ & $\mathrm{RMSE}^{\mathrm{b}}$ & $\mathrm{NMB}^{\mathrm{b}}(\%)$ \\
& & & \\
Temp $\left({ }^{\circ} \mathrm{C}\right)$ & $0.89(\geq 0.8)$ & $0.75(\leq \pm 0.5)$ & 1.90 & 2.68 \\
Wspd. $\left(\mathrm{m} \mathrm{s}^{-1}\right)$ & $0.66(\geq 0.6)$ & $0.65(\leq \pm 0.5)$ & $1.45(\leq \pm 2.0)$ & 37.81 \\
Wdir. $\left({ }^{(}\right)$ & 0.77 & $7.72(\leq \pm 10)$ & 85.88 & 4.24 \\
Ozone (ppbv) & 0.84 & 9.53 & 37.15 & $4.83(\leq 15)$ \\
& \\
= temperature; Wspd. = wind speed; Wdir. = wind direction. \\
the index of agreement; MB is the mean bias; RMSE is the root mean square error; NMB is the normalized mean bias.
\end{tabular}
influence mechanism of WWD on ground-level ozone

As variations in ozone concentration are directly caused by physical and chemical processes(Zhu et al., 2015), the fact that peripheral circulation of a typhoon affects ozone concentration can be discussed using an IPR analysis. The following processes were taken into account in this analysis: (1) advective transport (ADV), which is strongly related to wind and ozone concentration gradients from upwind areas to downwind areas; (2) vertical mixing (VMIX) caused by atmospheric turbulence and vertical gradients of ozone concentrations, which are related to variations in the PBL(Zhang and Rao, 1999; Gao et al., 2017); (3) chemistry (CHEM), which is the result of chemical calculations that include ozone chemical production and consumption; and (4) convective processes (CONV), i.e. the ozone contribution due to convective movements. Complete details on the analytical process of the WRF-Chem model can be found in previous studies(J. Gao et al., 2016; H. Zhang et al., 2014) and in the WRF-Chem user guide. 
ozone concentrations.

It can be seen from Fig. 6b-e: during the period from 08:00 to 20:00 on July 5-10, the contributions of CONV in PBL
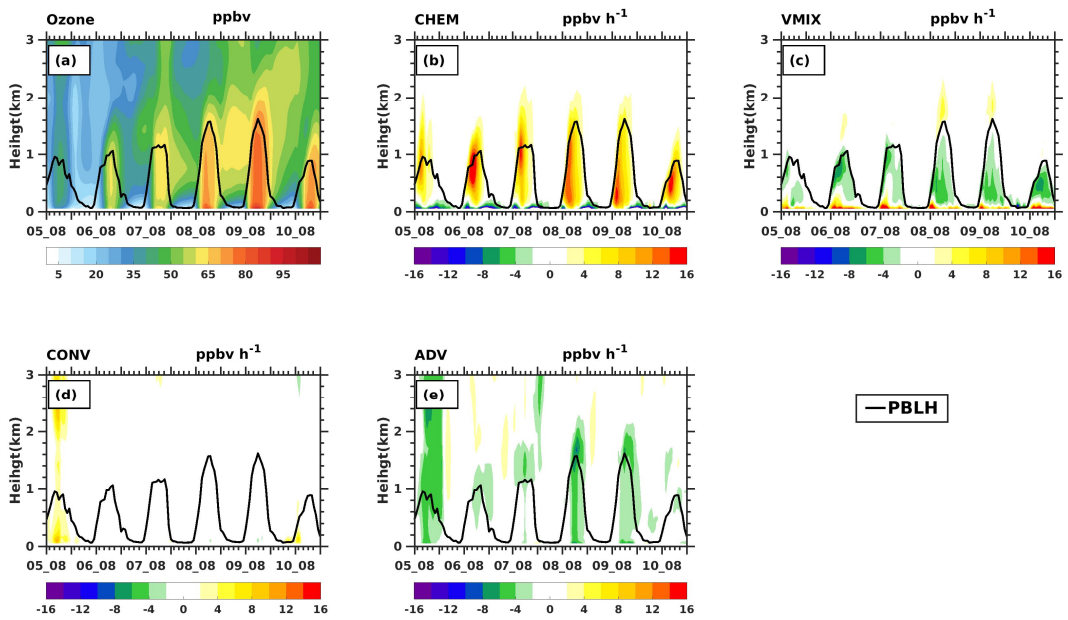

-PBLH

Figure 6. The profile evolution of averaged (a) ozone concentration and (b)-(e) CHEM, VMIX, CONV, and ADV of region D0 from 08:00 5

July to 20:00 10 July. The black lines denote the planetary boundary layer height(PBLH).

In order to investigate the cause of the continued increase of the daytime ozone concentration during the sustained 

concentration at any location at time $\mathrm{t}+1$ follows Eq. (1):

where $C_{t+1}$ and $C_{t}$ are the ozone concentrations at time $t+1$ and time $t$, respectively. SUM $M_{t+1}$ is the net change in contributions from all of the physical and chemical processes from time $t$ to time $t+1$, and is shown in Eq. (2):

$$
\mathrm{SUM}_{\mathrm{t}+1}=\mathrm{ADV}_{\mathrm{t}+1}+\mathrm{CHEM}_{\mathrm{t}+1}+\mathrm{VMIX}_{\mathrm{t}+1}+\mathrm{CONV}_{\mathrm{t}+1} \text {. }
$$

As specified in Eqs. (1) and (2), ozone concentration is a cumulative amount. Then, according to Eq. (1), we obtain:

$$
\mathrm{C}_{\mathrm{t}+24}-\mathrm{C}_{\mathrm{t}}=\sum_{\mathrm{j}=1}^{\mathrm{j}=24} \mathrm{SUM}_{\mathrm{t}+\mathrm{j}},(\mathrm{t}=08: 00,09: 00, \ldots, 20: 00),
$$

where $\mathrm{C}_{t}$ and $\mathrm{C}_{\mathrm{t}+24}$ are the ozone concentrations at the corresponding time on two adjacent days. For example, if $\mathrm{C}_{t}$ is the ozone concentration at 8:00 in the morning on a certain day, $\mathrm{C}_{\mathrm{t}+24}$ represents the ozone concentration at 8:00 in the next morning. $\mathrm{SUM}_{\mathrm{t}+\mathrm{j}}$ is the sum of the contributions from all of the physical and chemical processes at the corresponding time over the time slots. For example, when $t$ is 08:00, $\mathrm{SUM}_{08+1}$ indicates the SUM at 9:00 in the morning, and $\mathrm{SUM}_{08+24}$ indicates the SUM at 8:00 in the next morning. To give the daytime average ozone concentration difference of two adjacent days, we use 08:00 and 20:00 as the daytime and nighttime boundaries to reprocess the hourly data into a half-day average. If the daytime average ozone concentrations for two adjacent days are denoted as $\mathrm{C}_{\mathrm{d} 1}$ and $\mathrm{C}_{\mathrm{d} 2}$, the difference between the daytime average ozone concentrations on two adjacent days can be further expressed by three continuous contribution terms from 09:00 on the first day (d1) to 20:00 on the second day (d2):

$$
\mathrm{C}_{\mathrm{d} 2}-\mathrm{C}_{\mathrm{d} 1}=\frac{1}{\mathrm{~N}} \sum_{\mathrm{t} 1=09}^{\mathrm{t} 1=20}(\mathrm{t} 1-8) \cdot \mathrm{SUM}_{\mathrm{t} 1}+\sum_{\mathrm{t} 2=21}^{\mathrm{t} 2=08} \mathrm{SUM}_{\mathrm{t} 2}+\frac{1}{\mathrm{~N}} \sum_{\mathrm{t} 3=09}^{\mathrm{t} 3=20}(21-\mathrm{t} 3) \cdot \mathrm{SUM}_{\mathrm{t} 3}
$$

where $\mathrm{C}_{\mathrm{d} 2}$ and $\mathrm{C}_{\mathrm{d} 1}$ are the daytime average ozone concentrations on two adjacent days. $\mathrm{N}$ is the total number of time slots for the daytime period. Due to the daytime period is between 08:00-20:00, $\mathrm{N}$ is 13 . When the right side of Eq. (4) $>0$, the daytime average ozone concentration will increase compared to the daytime average concentration from the previous day, and vice versa. The three terms on the right side of Eq. (4) are referred to as $\mathrm{SUM}_{\mathrm{d} \_ \text {d1 }}, \mathrm{SUM}_{\mathrm{n}_{-} \mathrm{d} 1}$, and $\mathrm{SUM}_{\mathrm{d} \_\mathrm{d} 2}$, respectively. $\mathrm{SUM}_{\mathrm{d} \_\mathrm{d} 1}$ and $\mathrm{SUM}_{\mathrm{d} \_\mathrm{d} 2}$ reflect the daytime contributions on two adjacent days. $\mathrm{SUM}_{\mathrm{n} \_\mathrm{d} 1}$ reflects the 
nighttime contribution to difference in daytime average concentration (DDAC) between the two adjacent days. The sum of these three terms is referred to as TOTAL_SUM. It can be seen from Eq. (4): TOTAL_SUM is consistent with the evolution of daytime average ozone concentration, that is, when TOTAL_SUM $>0$, daytime average ozone concentration increases; when TOTAL_SUM $<0$, daytime average ozone concentration decreases. It worthy note that the ozone chemistry between the daytime and nighttime is totally different. The SUM value during daytime is always positive while the SUM of the nighttime is always negative. In terms of the daily daytime variation, the separated three terms as precursors) could also contribute to the daytime ozone increase of the next day. It can be seen from Fig. 7, during the daytime of 6-9 July, TOTAL_SUM was positive, and the corresponding daytime average ozone concentrations gradually increased; On the 10 July, TOTAL_SUM was negative, and daytime average ozone concentration began to decrease;

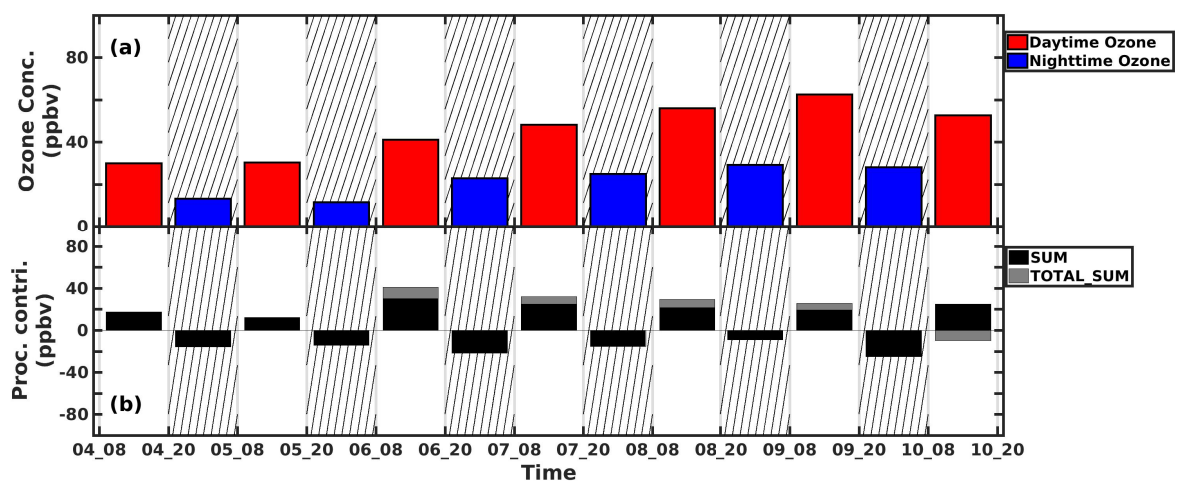

Figure 7. (a) daytime and nighttime ozone concentrations and (b) SUM and TOTAL_SUM on the ground within region D0 during 08:00 4

$$
\mathrm{C}_{\mathrm{d} 2}-\mathrm{C}_{\mathrm{d} 1}=\frac{1}{\mathrm{~N}} \sum_{\mathrm{t} 1=09}^{\mathrm{t} 1=20}(\mathrm{t} 1-8) \cdot \mathrm{CHEM}_{\mathrm{t} 1}+\sum_{\mathrm{t} 2=21}^{\mathrm{t} 2=08} \mathrm{CHEM}_{\mathrm{t} 2}+\frac{1}{\mathrm{~N}} \sum_{\mathrm{t} 3=09}^{\mathrm{t} 3=20}(21-\mathrm{t} 3) \cdot \mathrm{CHEM}_{\mathrm{t} 3}
$$




$$
+\frac{1}{\mathrm{~N}} \sum_{\mathrm{t} 1=09}^{\mathrm{t} 1=20}(\mathrm{t} 1-8) \cdot \mathrm{ADV}_{\mathrm{t} 1}+\sum_{\mathrm{t} 2=21}^{\mathrm{t}=08} \mathrm{ADV}_{\mathrm{t} 2}+\frac{1}{\mathrm{~N}} \sum_{\mathrm{t} 3=09}^{\mathrm{t}=20}(21-\mathrm{t} 3) \cdot \mathrm{ADV}_{\mathrm{t} 3}
$$

305

306

307

308

309

310

311

312

The decomposed items are respectively denoted as:

TOTAL_SUM_CHEM $=\frac{1}{\mathrm{~N}} \sum_{\mathrm{t} 1=09}^{\mathrm{t} 1=20}(\mathrm{t} 1-8) \cdot \mathrm{CHEM}_{\mathrm{t} 1}+\sum_{\mathrm{t} 2=21}^{\mathrm{t} 2=08} \operatorname{CHEM}_{\mathrm{t} 2}+\frac{1}{\mathrm{~N}} \sum_{\mathrm{t} 3=09}^{\mathrm{t}=20}(21-\mathrm{t} 3) \cdot \mathrm{CHEM}_{\mathrm{t} 3}$,

TOTAL_SUM_VMIX $=\frac{1}{\mathrm{~N}} \sum_{\mathrm{t} 1=09}^{\mathrm{t} 1=20}(\mathrm{t} 1-8) \cdot \mathrm{VMIX}_{\mathrm{t} 1}+\sum_{\mathrm{t} 2=21}^{\mathrm{t}=08} \mathrm{VMIX}_{\mathrm{t} 2}+\frac{1}{\mathrm{~N}} \sum_{\mathrm{t} 3=09}^{\mathrm{t}=20}(21-\mathrm{t} 3) \cdot \mathrm{VMIX}_{\mathrm{t} 3}$,

TOTAL_SUM_CONV $=\frac{1}{\mathrm{~N}} \sum_{\mathrm{t} 1=09}^{\mathrm{t} 1=20}(\mathrm{t} 1-8) \cdot \mathrm{CONV}_{\mathrm{t} 1}+\sum_{\mathrm{t} 2=21}^{\mathrm{t} 2=08} \mathrm{CONV}_{\mathrm{t} 2}+\frac{1}{\mathrm{~N}} \sum_{\mathrm{t} 3=09}^{\mathrm{t}=20}(21-\mathrm{t} 3) \cdot \mathrm{CONV}_{\mathrm{t} 3}$,

TOTAL_SUM_ADV $=\frac{1}{\mathrm{~N}} \sum_{\mathrm{t} 1=09}^{\mathrm{t} 1=20}(\mathrm{t} 1-8) \cdot \mathrm{ADV}_{\mathrm{t} 1}+\sum_{\mathrm{t} 2=21}^{\mathrm{t} 2=08} \mathrm{ADV}_{\mathrm{t} 2}+\frac{1}{\mathrm{~N}} \sum_{\mathrm{t} 3=09}^{\mathrm{t}=20}(21-\mathrm{t} 3) \cdot \mathrm{ADV}_{\mathrm{t} 3} \cdot$

Equation (5) shows that the daytime average ozone concentration difference of two adjacent days is determined by TOTAL_SUM_CHEM, TOTAL_SUM_VMIX, TOTAL_SUM_CONV and TOTAL_SUM_ADV. 

ground.

\begin{tabular}{ccccccc}
\hline $\begin{array}{c}\text { Period } \\
\text { (ppbv) }\end{array}$ & 4_08-5_20 & 5_08_6_20 & 6_08-7_20 & 7_08-8_20 & 8_08-9_20 & 9_08-10_20 \\
\hline $\begin{array}{c}\text { TOTAL_SUM } \\
\text { _CHEM }\end{array}$ & -138.16 & -113.817 & -133.376 & -96.6765 & -75.1189 & -133.958 \\
$\quad \begin{array}{c}\text { TOTAL_SUM } \\
\text { VMMIX }\end{array}$ & 118.845 & 113.4034 & $\mathbf{1 3 1 . 0 9 1 5}$ & 88.912 & 70.3796 & 105.2292 \\
$\quad$ & & & & \\
$\quad \begin{array}{l}\text { TOTAL_SUM } \\
\text { CONV }\end{array}$ & 33.7043 & 13.4999 & -1.725 & 0.8075 & -2.7115 & 12.1332 \\
$\begin{array}{c}\text { TOTAL_SUM_ADV } \\
\text { TOTAL_SUM_CAC }\end{array}$ & -13.9651 & -3.3129 & 10.9665 & 15.0615 & 14.0091 & 6.9084 \\
\hline TOTAL_SUMs & 14.3893 & 13.0863 & -4.0095 & -6.9570 & -7.4508 & -16.5956 \\
\hline
\end{tabular}

Note: the highlighted column indicate the non-attainment (national-II air quality standard) ozone period. TOTAL_SUM_CAC is the sum of the TOTAL_SUM_(CHEM+VMIX+CONV).

On the ground, regarding to the daily variability of the daytime ozone levels during the episode, the details budget of the TOTAL_SUM_CHEM, TOTAL_SUM_VMIX and TOTAL_SUM_CONV during the episode are presented in Table 4. More specifically, the CHEM contribution is always negative and VMIX contribution is always positive on the ground which should be the result of the surface NO-titration effect. The CONV contribution is relatively small during the episode (columns highlighted by brown color), while the ADV contribution significantly increased from negative value to positive value from 4 July to 10 July. The TOTAL_SUMs term is the sum of all the four processes $(\mathrm{CHEM}+\mathrm{VMIX}+\mathrm{CONV}+\mathrm{ADV})$, which show a large daytime ozone enhancement from 5 July to 9 July and a ozone decrease on 10 July. By calculating a sum of CHEM+VMIX+CONV ( TOTAL_SUM_CAC in the Table 4), we found this three processes changed to negative values during the episode period, while the ADV term changed to positive values and determined the sustained increase of daytime ozone. The results indicate that both the VMIX and ADV enhancement contributed to the daily increase of daytime ozone concentration from 6 to 9 July on the ground. 
of vertical profiles of accumulative CHEM contribution on 5 July and 7 July (Fig. 8a). The CHEM increase in PBL

CHEM enhancement above the ground should be due to the increase in photochemical formations of precursors
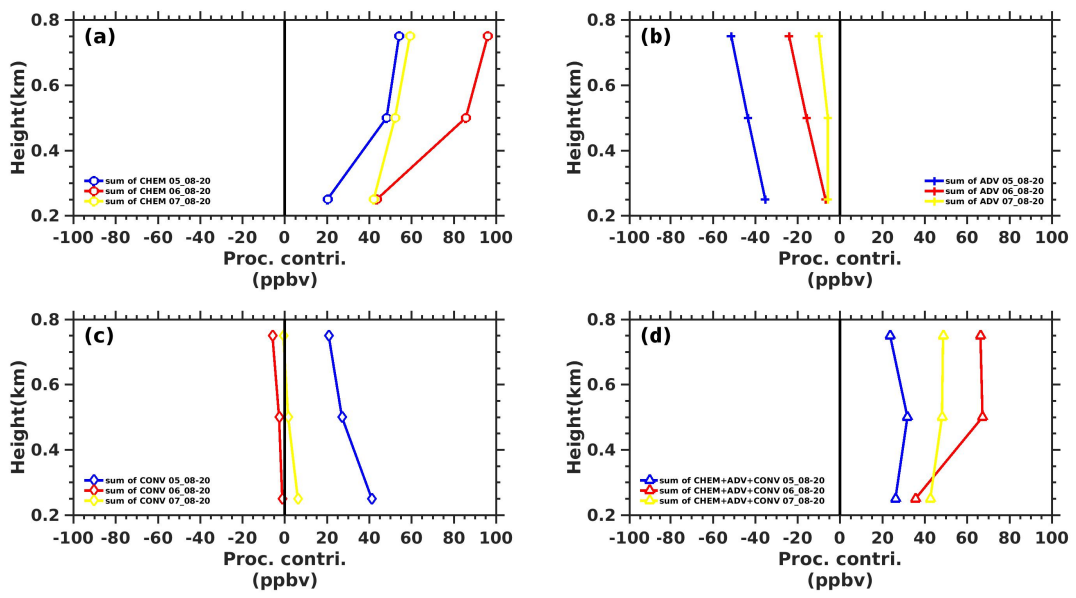

contribution to the continue enhancement of ground-level ozone via the VMIX processes.

\section{Conclusions}

It is widely reported that the peripheral circulation of typhoon favors for the sustained ozone episodes. However, the 

contributors to the enhancement of ozone levels, while the ADV and CONV are always negative or small values. But regarding the daily variability of the daytime ozone levels during the episode, the day-to-day variation of the daytime ozone levels do not determined by the daily variation of daytime CHEM and VMIX, but the ADV term. By a detail day-to-day analysis, it is found that the decrease of the negative ADV on the ground and throughout the PBL play an important role. The integrated effect of the day-to-day variation of the accumulative CHEM above the ground and accumulative ADV contribution throughout the PBL determined the overall day-to-day daytime ozone variation through the VMIX process. The enhanced VMIX contribution associated both to the enhanced CHEM and enhanced ADV in the above PBL.

Results show that the weak subsidence associated with typhoon periphery provide the premise for the clear sky and warmer air, which is conducive for the ozone photolysis formation in planetary boundary layer (PBL) above the ground where is dominated by NO-titration effect. The WWD induced by the peripheral circulation of typhoon system provide the premise for the enhanced contribution to ozone levels from daily ADV variation throughout the whole PBL, and the increased contribution to the continue enhancement of ground-level ozone via the VMIX processes. It shows that the peripheral characteristics of approaching typhoon not only form the ozone episode by the enhanced photochemical reactions but also the increase in pollution accumulation throughout the PBL due to the weak wind deepening up to $3 \sim 5$ $\mathrm{km}$ (but not a stability condition in thermodynamics). This result explains why daytime ozone continues to increase, although the photochemical contribution began to decrease during the event. It also indicate the important role of the WWD in the lower troposphere for the formation of sustained ozone episodes due to the peripheral circulation of the typhoon, which helps to better predict the daily changes of daytime ozone levels. 
Author contributions. YL and XZ designed and led the study. JG performed model simulations. XZ and YL analyzed data

400

401

Competing interests. The authors declare that they have no conflict of interest.

402

Acknowledgements. We would like to acknowledge the National Centers for Environmental Prediction (NCEP) for the

Final Operational Global Analysis data which are freely obtained from the website https://rda.ucar.edu/datasets/ds083.2/.

The hourly ambient surface $\mathrm{O}_{3}$ concentration are real-timely released by Ministry of Environmental Protection, China on the website http://www.aqistudy.cn/, freely downloaded from http://106.37.208.233:20035/. The meteorological datas, such as the wind profiler data, automatic weather station data, cloud data and so on, were provided by the China Meteorological Administration and downloaded from http://172.22.1.175. This research was supported by the National Natural Science Foundation of China (Grant 41961160728), the Guangdong Province Science and Technology Planning Project of China (Grant 2017A050506003), and Shenzhen Peacock Teams Plan (KQTD20180411143441009). 


\section{- References}

Aunan, K., Berntsen, T. K., and Seip, H. M.: Surface Ozone in China and its Possible Impact on Agricultural Crop Yields, AMBIO J. Hum. Environ., 29, 294-301, 2000.

Chan, A., Fung, J. C. H., and Lau, A. K. H.: Influence of urban morphometric modification on regional boundary-layer dynamics, J. Geophys. Res. Atmospheres, 118, 2729-2747, 2013.

Chen, X. L., Fan, S. J., Jiang-Nan, L. I., Ji, L., Wang, A. Y., and Soi-Kun, F.: typical weather characteristics associated with air pollution in Hong Kong area, J. Trop. Meteorol., 014, 101-104, 2008.

Chen, Z., Zhuang, Y., Xie, X., Chen, D., Cheng, N., Yang, L., and Li, R.: Understanding long-term variations of meteorological influences on ground ozone concentrations in Beijing During 2006-2016., Environ. Pollut., 245, 29-37, 2018.

Cheng, N. L., Li, Y. T., Zhang, D. W., Chen, T., Wang, X., Huan, N., Chen, C., and Meng, F.: Characteristics of Ozone over Standard and Its Relationships with Meteorological Conditions in Beijing City in 2014, Environ. Sci., 37, 2016.

Deng, T., Wang, T., Wang, S., Zou, Y., Yin, C., Li, F., Liu, L., Wang, N., Song, L., and Wu, C. and: Impact of typhoon periphery on high ozone and high aerosol pollution in the Pearl River Delta region, Sci. Total Environ., 668, 617-630, 2019.

Doll, D. C.: Guideline for Regulatory Application of the Urban Airshed Model, 1991.

Emery, C., Tai, E., and Yarwood, G.: Enhanced meteorological modeling and performance evaluation for two texas episodes, in: Prepared for the Texas Natural Resource Conservation Commission, by Environ International Corp, 2007.

Felzer, B. S., Cronin, T., Reilly, J. M., Melillo, J. M., and Wang, X.: Impacts of ozone on trees and crops, Comptes Rendus Géoscience, 339, 784-798, 2007.

Feng, Y., Wang, A., Wu, D., and $\mathrm{Xu}, \mathrm{X}$.: The influence of tropical cyclone Melor on PM(10) concentrations during an aerosol episode over the Pearl River Delta region of China: Numerical modeling versus observational analysis, Atmos. Environ., 41, p.4349-4365, 2007.

Feng, Z., Hu, E., Wang, X., Jiang, L., and Liu, X.: Ground-level O-3 pollution and its impacts on food crops in China: A review, Environ. Pollut., 199, 42-48, 2015.

Forkel, R., Werhahn, J., Hansen, A. B., Mckeen, S., Peckham, S., Grell, G., and Suppan, P.: Effect of aerosol-radiation feedback on regional air quality - A case study with WRF/Chem, Atmos. Environ., 53, 202-211, 2012.

Gao, J., Zhu, B., Xiao, H., Kang, Hou, X., and Shao, P.: A case study of surface ozone source apportionment during a high concentration episode, under frequent shifting wind conditions over the Yangtze River Delta, China, Sci. Total Environ., 544, 853-863, 2016.

Gao, J., Zhu, B., Xiao, H., Kang, H., Hou, X., Yin, Y., Zhang, L., and Miao, Q.: Diurnal variations and source apportionment of ozone at the summit of Mount Huang, a rural site in Eastern China, Environ. Pollut., 222, 513-522, 2017. 
Gao, J., Li, Y., Zhu, B., Hu, B., Wang, L., and Bao, f.: What have we missed when studying the impact of aerosols on surface ozone via changing photolysis rates?, Atmospheric Chem. Phys., 10831-10844, 2020.

Giorgi, F. and Meleux, F.: Modelling the regional effects of climate change on air quality, Comptes Rendus Geosci., 339, 721-733, 2007.

Grell, G. A., Peckham, S. E., Schmitz, R., Mckeen, S. A., Frost, G., Skamarock, W. C., and Eder, B.: Fully coupled "online" chemistry within the WRF model, 2005.

Han, H., Liu, J., Shu, L., Wang, T., and Yuan, H.: Local and synoptic meteorological influences on daily variability of summertime surface ozone in eastern China, Atmospheric Chem. Phys., 1-51, 2019.

Hu, J., Chen, J., Ying, Q., and Zhang, H.: One-Year Simulation of Ozone and Particulate Matter in China Using WRF/CMAQ Modeling System, Atmospheric Chem. Phys. Discuss., 16, 10333-10350, 2016.

Huang, J., Liu, H., Crawford, J. H., Chan, C., Considine, D. B., Zhang, Y., Zheng, X., Zhao, C., Thouret, V., and Oltmans, S. J.: Origin of springtime ozone enhancements in the lower troposphere over Beijing: in situ measurements and model analysis, 15, 5161-5179, 2015.

Jiang, Y. C., Zhao, T. L., Liu, J., Xu, X. D., Tan, C. H., Cheng, X. H., Bi, X. Y., Gan, J. B., You, J. F., and Zhao, S. Z.: Why does surface ozone peak before a typhoon landing in southeast China?, ATMOSPHERIC Chem. Phys., 15, 13331-13338, 2015.

Kwok, R. H. F., Fung, J. C. H., Lau, A. K. H., and Fu, J. S.: Numerical study on seasonal variations of gaseous pollutants and particulate matters in Hong Kong and Pearl River Delta Region, J. Geophys. Res. Atmospheres, 115, 2010.

Lai, L. Y. and Sequeira, R.: Visibility degradation across Hong Kong: its components and their relative contributions, Atmos. Environ., 35, 5861-5872, 2001.

Li, J., Wang, Z., Akimoto, H., Gao, C., Pochanart, P., and Wang, X.: Modeling study of ozone seasonal cycle in lower troposphere over east Asia, J. Geophys. Res. Atmospheres, 112, 2007.

Li, Y., Lau, A. K. H., Fung, J. C. H., Ma, H., and Tse, Y.: Systematic evaluation of ozone control policies using an Ozone Source Apportionment method, Atmos. Environ., 76, 136-146, https://doi.org/10.1016/j.atmosenv.2013.02.033, 2013.

Li, Y., Lau, A., Wong, A., and Fung, J.: Decomposition of the wind and nonwind effects on observed year-to-year air quality variation, J. Geophys. Res. Atmospheres, 119, 6207-6220, 2014.

Lin, X., Yuan, Z., Yang, L., Luo, H., and Li, W.: Impact of Extreme Meteorological Events on Ozone in the Pearl River Delta, China, Aerosol Air Qual. Res., 19, 1307-1324, https://doi.org/10.4209/aaqr.2019.01.0027, 2019.

Liu, J., Wu, D., Fan, S. J., Liao, Z. H., and Deng, T.: Impacts of precursors and meteorological factors on ozone pollution in Pearl River Delta, Zhongguo Huanjing Kexuechina Environ. Sci., 37, 813-820, 2017.

Lu, R., Turco, R. P., and Jacobson, M. Z.: An integrated air pollution modeling system for urban and regional scales: 2. Simulations for SCAQS 1987, J. Geophys. Res. Atmospheres, 102, 6081-6098, https://doi.org/10.1029/96JD03502, 1997. 
Ministry of Ecology and Environment of China: Chinese State of the Environment Bulletin, 1-54, 2016.

Organization, W. H.: WHO Air quality guidelines for particulate matter, ozone, nitrogen dioxide and sulfur dioxide - Global update 2005, 2005.

Shu, L., Xie, M., Wang, T., Gao, D., Chen, P., Han, Y., Li, S., Zhuang, B., and Li, M.: Integrated studies of a regional ozone pollution synthetically affected by subtropical high and typhoon system in the Yangtze River Delta region, China, Atmospheric Chem. Phys., 16, 15801-15819, 2016.

Shu, L., Wang, T., Xie, M., Li, M., Zhao, M., Zhang, M., and Zhao, X.: Episode study of fine particle and ozone during the CAPUM-YRD over Yangtze River Delta of China: Characteristics and source attribution, Atmos. Environ., 203, 87-101, https://doi.org/10.1016/j.atmosenv.2019.01.044, 2019.

Skamarock, W. C., Klemp, J. B., Dudhia, J., Gill, D. O., Barker, D. M., Duda, M. G., Huang, X.-Y., Wang, W., and Powers, J. G.: A Description of the Advanced Research WRF Version 3, 125, n.d.

Tan, Z., Lu, K., Jiang, M., Su, R., Dong, H., Zeng, L., Xie, S., Tan, Q., and Zhang, Y.: Exploring ozone pollution in Chengdu, southwestern China: A case study from radical chemistry to O3 -VOC-NOx sensitivity, Sci. Total Environ., 636, 775-786, 2018.

Wang, N.: Guangdong Haze Weather Bulletin, 21 pp., 2017.

Wang, T., Lam, K. S., Lee, A. S. Y., Pang, S. W., and Tsui, W. S.: Meteorological and Chemical Characteristics of the Photochemical Ozone Episodes Observed at Cape D’Aguilar in Hong Kong, J. Appl. Meteorol., 37, 1167-1178, 1998.

Wang, T., Wu, Y. Y., Cheung, T. F., and Lam, K. S.: A study of surface ozone and the relation to complex wind flow in Hong Kong, Atmos. Environ., 35, 3203-3215, 2001.

Wang, X., Zhang, Y., Hu, Y., Zhou, W., and Russell, A. G.: Process analysis and sensitivity study of regional ozone formation over the Pearl River Delta, China, during the PRIDE-PRD2004 campaign using the CMAQ model, Atmospheric Chem. Phys. Discuss., 9, 635-645, 2009.

Wang, Z., Li, J., Wang, X., Pochanart, P., and Akimoto, H.: Modeling of Regional High Ozone Episode Observed at Two Mountain Sites (Mt. Tai and Huang) in East China, J. Atmospheric Chem., 55, 253-272, 2006.

Wu, D., Tie, X., Li, C., Ying, Z., Lau, K. H., Huang, J., Deng, X., and Bi, X.: An extremely low visibility event over the Guangzhou region: A case study, Atmos. Environ., 39, p.6568-6577, 2005.

Wu, M., Wu, D., Fan, Q., Wang, B. M., Li, H. W., and Fan, S. J.: Observational studies of the meteorological characteristics associated with poor air quality over the Pearl River Delta in China, Atmospheric Chem. Phys., 13, 10755-10766, https://doi.org/10.5194/acp-13-10755-2013, 2013.

Zaveri, R. A. and Peters, L. K.: A new lumped structure photochemical mechanism for large-scale applications, J. Geophys. Res. Atmospheres, 104, 30387-30415, 1999.

Zaveri, R. A., Easter, R. C., Fast, J. D., and Peters, L. K.: Model for Simulating Aerosol Interactions and Chemistry (MOSAIC), J. Geophys. Res. Atmospheres, 113, 2008.

Zhang, H., DeNero, S. P., Joe, D. K., Lee, H.-H., Chen, S.-H., Michalakes, J., and Kleeman, M. J.: 
Development of a Source Oriented version of the WRF- Chem Model and its Application to the California Regional PM10/PM2.5 Air Quality Study, 20, 2014.

Zhang, J. and Rao, S. T.: The Role of Vertical Mixing in the Temporal Evolution of Ground-Level Ozone Concentrations, J. Appl. Meteorol., 38, 1674-1691, 1999.

Zhang, J. P., Zhu, T., Zhang, Q. H., Li, C. C., Shu, H. L., Ying, Y., Dai, Z. P., Wang, X., Liu, X. Y., and Liang, A. M.: The impact of circulation patterns on regional transport pathways and air quality over Beijing and its surroundings, Atmospheric Chem. Phys., 12, 5031-5053, 2012.

Zhang, Y., Wen, X. Y., and Jang, C. J.: Simulating chemistry-aerosol-cloud-radiation-climate feedbacks over the continental U.S. using the online-coupled Weather Research Forecasting Model with chemistry (WRF/Chem), Atmos. Environ., 44, p.3568-3582, 2010.

Zhang, Y., Mao, H., Ding, A., Zhou, D., and Fu, C.: Impact of synoptic weather patterns on spatio-temporal variation in surface $\{\mathrm{O} 3\}$ levels in Hong Kong during 1999-2011, Atmos. Environ., 73, 41-50, 2013.

Zhu, B., Kang, H., Zhu, T., Su, J., Hou, X., and Gao, J.: Impact of Shanghai urban land surface forcing on downstream city ozone chemistry: URBAN LAND-SURFACE FORCING ON OZONE, J. Geophys. Res. Atmospheres, 120, 4340-4351, https://doi.org/10.1002/2014JD022859, 2015.

Ziomas, I. C., Melas, D., Zerefos, C. S., Bais, A. F., and Paliatsos, A. G.: Forecasting peak pollutant levels from meteorological variables, Atmos. Environ., 29, 3703-3711, 1995. 